Original article

Corresponding Author:

Javier Fernandez-Navarro, University of Granada, Faculty of Sport Sciences, Carretera de Alfacar s/n, Granada, 18071, Spain

Email: javierfernandez@ugr.es

\title{
Evaluating the effectiveness of styles of play in elite soccer
}

\author{
Javier Fernandez-Navarro ${ }^{1}$, Luis Fradua ${ }^{1}$, Asier Zubillaga ${ }^{2}$ and \\ Allistair P. McRobert ${ }^{3}$ \\ ${ }^{1}$ Department of Physical Education and Sport, University of Granada, Granada, Spain \\ ${ }^{2}$ Department of Physical Education and Sport, UPV/EHU University of the Basque \\ Country, Vitoria-Gasteiz, Spain \\ ${ }^{3}$ The Football Exchange, Research Institute for Sport and Exercise Sciences, Liverpool \\ John Moores University, Liverpool, UK
}

\begin{abstract}
The aim of this study was to evaluate the effectiveness of styles of play in soccer and the influence of contextual variables (i.e. match status, venue, and quality of opposition). Team possessions $(n=68,766)$ from the 380 matches of the 2015-2016 English Premier League season were collected for this study. The Possession Effectiveness Index (PEI), based on Expected Goals and Ball Movement Points metrics, was used to measure the effectiveness of team possessions. Linear mixed models were applied to analyse the influence of contextual variables on the effectiveness score for each style. Results showed that the effectiveness of Direct Play, Counterattack, Maintenance and Crossing significantly increased when teams were winning by two or more goals. Counterattack increased its effectiveness when teams were winning by one goal and reduced its effectiveness when losing by one goal. The effectiveness of Direct Play increased when losing by two goals or more. Playing away negatively affected the effectiveness of Direct Play, Maintenance and High Pressure. In addition, playing against a stronger opposition reduced the effectiveness of all styles of play. The results suggest that the effectiveness of styles of play changes under specific circumstances and that not all contextual variables affect them in the same way.
\end{abstract}

\section{Keywords}

match analysis, performance analysis, football, tactics, mixed models 


\section{Introduction}

The use of different methods and approaches for measuring tactical behaviour in soccer is increasing in research. ${ }^{1,2}$ The analysis of tactical behaviour provides information that can be used by teams to enhance performance. Styles of play are general tactical behaviours of the whole team that aim to achieve the attacking and defensive objectives in the game. ${ }^{3,4}$ Therefore, styles of play gain importance in performance analysis as they describe the way that teams play. In order to identify and examine styles of play in soccer, researchers have measured different tactical variables or performance indicators, such as ball possession, direction of passes or ball regains. Recently, researchers have used multiple performance indicators and analytical approaches to measure styles of play. ${ }^{3,5,6}$ Furthermore, contextual variables such as match status, venue, and quality of opposition influence overall performance ${ }^{2}$ and a team's style of play. ${ }^{7,8}$

In addition to evaluating how performance indicators are associated with successful teams, ${ }^{9-12}$ researchers have assessed the effectiveness of specific attacking or defensive indicators. Collet ${ }^{13}$ evaluated the impact of ball possession on team success in five European leagues, UEFA, and FIFA tournaments from the period 2007-2010. They showed that ball possession predicted team success in domestic leagues, but it was a poor predictor when team quality and home advantage were included. Vogelbein et al. ${ }^{14}$ analysed ball possession recoveries of successful and unsuccessful teams during the Bundesliga 2010-2011 season and found that top teams required less time to regain ball possession, compared to other teams. Other researchers have focused on the effectiveness of set pieces such as free kicks ${ }^{15}, 16$ or penalty kicks ${ }^{17}$.

More recently, researchers have used multiple performance indicators to create behaviour indexes, multivariate statistical approaches and spatio-temporal analysis ${ }^{1}$. For example, Kempe et al. ${ }^{6}$ developed the Index of Game Control (IGC) and Index of Offensive Behaviour (IOB) using a combination of performance indicators, which were sensitive enough to differentiate tactical behaviours of teams in the Bundesliga 20092010 and FIFA World Cup 2010. Possession and direct play were the most common tactical approaches in soccer, however successful teams preferred possession play. Clemente and colleagues ${ }^{18,19}$ used positional data to generate metrics (e.g. weighted centroids, effective area of play) that evaluated attacking and defensive tactical behaviour. They suggest that the match period and ball possession status influence teams differently, specifically players' spatio-temporal relationships. Consequently, the approaches used in these studies entailed an advance in the performance analysis research area.

Moreover, the effectiveness of more complex tactical behaviours hashave also been analysed. Rein et al. ${ }^{20}$ used Voronoi diagrams to analyse pass effectiveness by evaluating how many defending outfield players it bypasses and the space it creates next to the opponent's goal. These measures were significantly related to success, therefore, bypassing opposing players and creating space next to the opponent's goal should be an objective for teams. However, the Euclidean distance was considered in the Voronoi 
diagrams analysed and maybe distances acknowledging players individualities would be a better approach. Ball possessions effectiveness for teams was also evaluated using a quantitative measure (i.e. yield) based on the difference between the probability of scoring a goal and the probability of receiving it. ${ }^{21}$ This measure was extended and applied to single actions in ball possessions. ${ }^{22}$ These approaches form the basis for novel effectiveness measures employed in soccer match analysis and analytics. These measures could be useful for coaches because they evaluate the effectiveness of attacking actions. However, more refined definitions of the strategies measured are required to improve the model.

New effectiveness metrics taking into account multiple variables have been developed recently. For example, expected goals $(\mathrm{xG})$ is a metric used to assess the chance of a shot resulting in a goal. ${ }^{23} \mathrm{xG}$ could provide a more sensitive measure to evaluate teams and players scoring performance when compared to other indicators such as total shots or shots on target. This metric is useful for coaches and practitioners due to the possibility of evaluating the amount of good or bad scoring chances that the team develops during competition. However, $\mathrm{xG}$ models have some criticisms, specifically the number of factors that influence shot effectiveness are often not included in models. More importantly, $\mathrm{xG}$ only calculates the average chance of scoring without accounting for differences between players and the quality of their finishing skill. Although this metric has become very popular for soccer analytics departments and broadcasters, its origins are unclear. Different blogs and websites show several options for calculating this metric in soccer and even in other team sports.

Despite the use of multiple effectiveness measures for quantifying soccer performance, research evaluating the effectiveness of styles of play in soccer match-play is scarce. Previous research assessed the effectiveness of counterattack and elaborate play, and stated that counterattacks were more effective when playing against an imbalanced defence. ${ }^{24,25}$ Nevertheless, more styles of play should be considered when analysing the style of play effectiveness. Knowing how effective styles of play are under specific conditions could help coaches and practitioners make decisions during competition and training. Therefore, the study aim was to use a novel approach to evaluate the effectiveness of styles of play in soccer, while quantifying the influence of contextual variables such as match status, venue and quality of the opposition. We expected that a winning status would increase the effectiveness of direct and counterattack styles, and a losing status would increase the possession-based styles. We also expected that playing away and facing a strong opposition would decrease the effectiveness of the styles of play measured.

\section{Methods}

\section{Match sample}

A total of 380 English Premier League (EPL) matches from the 2015-2016 season were used for the study. An equal number of matches (38 games for every team) from 20 teams participating in the league were available from STATS LLC. The validity and 
reliability of their computerised match analysis tracking system (STATS LLC, Chicago, IL, USA) havehas been previously quantified. ${ }^{26,27}$ This study had the approval from the Human Research Ethics Committee of the University of Granada.

\section{Procedure}

A total of 94,966 team possessions were extracted from the 380 EPL matches in the 2015-2016 season. For each of these possessions, a percentage membership score was provided for eight styles of play defined by STATS LLC (Table 1). Each team possession can have multiple scores across styles, therefore, a value between 0 and 100 was assigned to each style of play. Consequently, possessions can have maximum scores of 100 for several styles of play. For instance, a team possession could involve the use of Build Up (80\%), Sustained Threat (50\%), and Fast Tempo (25\%) styles. Team possessions with a score of 0 across all styles (e.g. quick turnovers of possession) and set pieces were removed from the dataset. After filtering, a total of 68,766 team possessions with a score above 0 were included in the model to evaluate playing style effectiveness. 
Direct Play Captures instances of play where teams attempt to move the ball quickly towards the opposition's goal through the use of long passes. Specifically, it looks at the distance gained forward every time a team makes use of any of the following events: pass, direct free-kick pass, indirect free-kick pass, cross, direct free-kick cross, indirect free-kick cross, goal kick, goalkeeper throw, goalkeeper kick, throw in, or clearance. The forward distance gained must be greater than 20 metres and reaches $100 \%$ at 40 metres.

Counterattack A team regains possession and moves the ball into an attacking area via passes, dribbles or a combination of both. The ball must reach a target location within the opposition's half. This location varies depending on the regain location. The speed of the transition from a regain to a target location determines the Counterattack value. The quicker the ball is moved up the pitch, the higher the Counterattack value. Counterattack regains include: goal keeper catch, goal keeper save, interception, clearance, header, tackle and block. Counterattack distance gained include: touch, dribbling, clearance and pass.

Maintenance Captures possessions in which a team looks to maintain possession of the ball within the defensive area of the pitch. The time spent in possession directly relates to the Maintenance membership value. The team must have a passage of play lasting more than 10 seconds. From then on, the membership value increases linearly up until 30 seconds where it reaches $100 \%$.

Build Up Captures long and controlled ball possessions - but is aimed at periods of play where a team is looking for opportunities to attack. The calculation is similar to Maintenance with the differences being the zone on the pitch and the time thresholds. The Build Up area is between the halfway line and the opposition's penalty area and the passage of play must last more than 8 seconds. From then on, the membership value increases linearly up until 25 seconds where it reaches $100 \%$.

Sustained Similar to Maintenance and Build Up. However, here the focus lies on possessions in the attacking third of the pitch. The time spent in possession must Threat be more than 6 seconds, reaching $100 \%$ at 20 seconds.

Fast Tempo Captures when the team is moving the ball quickly to increase the tempo and speed of the game. Fast Tempo looks at sequences of consecutive individual 'fast possessions'. An individual fast possession must occur in the opposition's half and can be achieved as follows: the player releases the ball to a team mate in less than 2 seconds, or the player dribbles at a high tempo.

Crossing It occurs if the ball is delivered from a wide area of the pitch with the intention of finding a teammate. All Crossing events in a possession are assigned a value of $100 \%$. The value assigned to the team possession can only be $0 \%$ or $100 \%$ depending on the occurrence of a crossing event. Crossing events are: cross, corner cross, direct free-kick cross and indirect free-kick cross.

High Pressure Captures how high up the pitch teams regain possession. The first factor taken into consideration is the location where the team wins the ball: High Press regains are those higher than 5 metres prior to the halfway line. The value increases linearly up until 15 metres into the opposition's half where it reaches $100 \%$. The second factor is the opposition's time in possession prior to the High Press regain happening. To retain the full value established based on the regain location, the opposition must have been in possession for at least 10 seconds. This time factor is introduced to try and capture controlled pressing efforts rather than 'counter press' regains. The combination of these two factors leads to the final High Press membership value. Regain events include: interception, header, tackle and block.
} 

conversion probability of a shot based on pitch location and type of finish (e.g., shot, headed shot). Shot location and shot type were the variables considered to calculate the $\mathrm{xG}$ metric. The $\mathrm{xG}$ assigns a quality value ranging from 0 to 1 for each shot at goal with a higher value indicating a greater likelihood of a scoring opportunity (see Figure 1). For instance, a headed shot from the central position on the edge of the six-yard box has an $\mathrm{xG}$ value of 0.3185 . In other words, $31.85 \%$ of shots taken from this position would end in a goal. Figure 2 shows an example of the $\mathrm{xG}$ values for all shots and headers for both teams in a whole match. This $\mathrm{xG}$ model is calculated using 31,384 shots from three seasons of EPL data (2011-2012, 2012-2013, 2013-2014). Thus, this provided the basis for the Expected Goals model to calculate the likelihood of a shot resulting in a goal. A detailed explanation of the $\mathrm{xG}$ model and multiple sources that cover this metric can be found in the study by Rathke ${ }^{23}$.

[insert Figure 1]

[insert Figure 2]

\section{Ball Movement Points (BMP)}

The BMP is developed based on data from six full EPL seasons (2009-2010 to 20142015). BMP measures each ball move in a possession, and ball moves are assessed according to the danger it causes to the opposition. A ball move is characterised by a move start zone (i.e. where the player receives the ball or where the ball is resumed after a foul or ball out of play) and a move end zone (i.e. where the ball is delivered). To calculate BMP; a score is given to a ball move based on the probability of that pass leading to a shot later in the play, according to past data. Then, to consider how dangerous the shots following a ball move were, the previous score given to ball moves was multiplied by the goal expectancy of the shot, similarly, according to past data. For example, an assist with a shot score of 0.61 that leads to a shot with an $\mathrm{xG}$ value of 0.45 would result in a BMP value of 0.27. BMP values can be positive if ball moves are successful or negative if possession is lost to the opposition. The negative score equals the value of ball moves which originate at that start zone. Therefore, large negative values entail that the missed opportunity was better in comparison with negative values. The BMP values of every move in a possession are summed to get the BMP value of the possession. For example, if a possession entails five moves, the sum of the BMP values of those five moves will be the final BMP value of the possession. In order to award BMP values, the pitch is divided into 34 zones as showed in Figure 3. Zones in attacking half are more detailed due to the increase in danger as the ball gets closer to the opponent's goal, and the difficulty involved in advancing into these areas. 
[insert Figure 3]

\section{Possession Effectiveness Index (PEI)}

To evaluate the effectiveness of team possessions $\mathrm{xG}$ and BMP were combined. In the cases were a team possession ended in a shot, BMP and $\mathrm{xG}$ values were added to create a Possession Effectiveness Index (PEI) value. The following equation shows how PEI is calculated for each team possession:

$$
P E I=\left(\sum_{i=1}^{n}{\text { positive } B M P_{i}}_{i}\right)+\text { negative } B M P+x G
$$

The aim of combining BMP and $\mathrm{xG}$ in the PEI was to reward the possessions in the sample that ended in a shot. This value was then multiplied by the styles of play scores to generate an effectiveness score for each style of play during the team possession. In addition, contextual variables match status (i.e. losing by two goals or more, losing by one goal, drawing, winning by one goal, and winning by two goals or more), venue (i.e. playing home or away) and quality of opposition (i.e., measured according to the difference in the teams ranking position at the end of the season), were recorreded for each team possession.

\section{Statistical analysis}

All statistical tests were conducted using the R statistical software. ${ }^{28}$ A linear mixed model was performed for each of the eight styles of play using the lme4 package. ${ }^{29}$ Matches and teams were considered as nesting levels in this 3-level hierarchical structure (i.e. possessions, matches, teams). Hence a cross-classified multilevel design ${ }^{30}$ was employed for the analysis. According to this structure, the variables match and team were modelled as random effects. The effectiveness score for each style of play was the dependent variable and contextual variables (i.e. match status, venue, and quality of opposition) were the fixed effects in the models. Random slopes for these fixed effects and their interactions were also checked in case they made a significant contribution to each model. A general multilevel-modelling strategy ${ }^{30}$ was employed for each model. Consequently, fixed and random effects were included in different steps from the simplest to the most complex. The following formula provides a reference of the fixed and random effects used to build the models:

$Y_{i j k}$

$$
\begin{aligned}
& =\gamma_{000}+\gamma_{100} \text { matchstatuslose } 2+\gamma_{200} \text { matchstatuslose } 1+\gamma_{300} \\
& \text { matchstatuswin } 1+\gamma_{400} \text { matchstatuswin } 2+\gamma_{010} \text { away }+\gamma_{020} \\
& \text { qualityopposition }+u_{00 k}+r_{0 j k}+\varepsilon_{i j k}
\end{aligned}
$$

$\gamma_{000}=$ team level intercept, $\gamma_{100}$ matchstatuslose $2=$ losing by two or more goals coefficient, $\gamma_{200}$ matchstatuslose $1=$ losing by one goal coefficient, $\gamma_{300}$ matchstatuswin $1=$ winning by one goal coefficient, $\gamma_{400}$ matchstatuswin $2=$ winning 
by two or more goals coefficient, $\gamma_{010}$ away $=$ playing away coefficient, $\gamma_{020}$ qualityopposition $=$ quality of opposition coefficient, $u_{00 k}=$ between-teams variation in intercepts, $r_{0 j k}=$ between-matches variation in intercepts, $\varepsilon_{i j k}=$ variation in possessions.

The Akaike information criterion (AIC) $)^{31}$ was used for model comparison in each step of the process. Lower values of the AIC indicated a better model. Chi-square likelihood ratio tests ${ }^{32}$ were also performed to compare models. In other words, models were compared by subtracting the log-likelihood of the new model from the value of the old one and considering the degrees of freedom equal to the difference in the number of parameters between the two models. Besides de AIC, a lower value of the chi-square loglikelihood test represented a better model and showed if the changes were significant. These comparisons were made after the addition of a new variable, random slope, or interaction to evaluate if the model improved. The maximum likelihood (ML) estimation was used for model comparison and restricted maximum likelihood (REML) estimation was employed for the refitted final best model of each style of play. ${ }^{30,} 32$ Homogeneity of variance and normal distribution of the residuals of the model were verified in order to check the assumptions of the mixed models. Marginal and conditional $\mathrm{R}^{2}$ metrics $^{33,34}$ were provided for each LMM as a measure of effect size. The level of significance was set to 0.05 .

\section{Results}

Table 2 shows the effectiveness for the eight styles of play measured in the English Premier League during the 2015-2016 season and the influence of contextual variables (i.e. match status, venue and quality of opposition). The results are presented in order, from the most to lest effective styles of play per possession (intercept scores) for Crossing (5.053), Fast Tempo (2.872), Sustained Threat (2.153), Counterattack (1.508), Build Up (1.496), High Pressure (0.678), Maintenance (0.660) and Direct Play (0.648) based on reference circumstances (i.e. drawing and playing home). 
Table 2. Effectiveness of the 8 styles of play controlling for contextual variables

\begin{tabular}{|c|c|c|c|c|c|c|c|c|}
\hline \multirow[b]{2}{*}{ Fixed effects } & \multicolumn{4}{|c|}{ Direct Play } & \multicolumn{4}{|c|}{ Counterattack } \\
\hline & $\beta(\mathrm{SE})$ & $95 \% \mathrm{CI}$ & $\mathrm{t}$ & $P$ & $\beta(\mathrm{SE})$ & $95 \% \mathrm{CI}$ & $\mathrm{t}$ & $P$ \\
\hline Intercept & $0.648(0.035)$ & $0.579,0.717$ & 18.342 & $<0.001$ & $1.508(0.078)$ & $1.356,1.660$ & 19.448 & $<0.001$ \\
\hline Match status ( -2 or more) & $0.178(0.062)$ & $0.056,0.301$ & 2.856 & 0.004 & $-0.040(0.184)$ & $-0.400,0.320$ & -0.218 & 0.828 \\
\hline Match status (-1) & $0.038(0.046)$ & $-0.051,0.128$ & 0.840 & 0.401 & $-0.312(0.136)$ & $-0.580,-0.045$ & -2.289 & 0.022 \\
\hline Match status $(+1)$ & $-0.024(0.045)$ & $-0.111,0.064$ & -0.532 & 0.595 & $0.355(0.134)$ & $0.093,0.617$ & 2.656 & 0.008 \\
\hline Match status ( +2 or more) & $0.155(0.061)$ & $0.036,0.274$ & 2.558 & 0.011 & $0.766(0.171)$ & $0.431,1.100$ & 4.482 & $<0.001$ \\
\hline Venue (away) & $-0.084(0.032)$ & $-0.146,-0.022$ & -2.657 & 0.008 & - & - & - & - \\
\hline Quality opposition & $-0.018(0.002)$ & $-0.022,-0.013$ & -7.294 & $<0.001$ & $-0.015(0.006)$ & $-0.028,-0.002$ & -2.313 & 0.023 \\
\hline Venue (away) * Quality opposition & - & - & - & - & - & - & - & - \\
\hline Random effects & Estimate & SD & & & Estimate & SD & & \\
\hline Match & 0.017 & 132 & & & 0.097 & 0.311 & & \\
\hline Venue & - & - & & & - & - & & \\
\hline Quality opposition & - & - & & & - & - & & \\
\hline Team & 0.009 & .093 & & & 0.020 & 0.142 & & \\
\hline Residuals & 10.298 & 209 & & & 18.706 & 4.325 & & \\
\hline $\begin{array}{l}\mathrm{R}^{2}(\mathrm{~m}) \\
\mathrm{R}^{2}\end{array}$ & & 0.00 & & & & 0.007 & & \\
\hline
\end{tabular}

$\beta$, beta coefficient; SE, standard error; CI, confidence interval. Statistical significance set at $P<0.05$.

Intercepts represent a draw and playing home. 
Fixed effects

Intercept

Match status (-2 or more)

Match status (-1)

Match status $(+1)$

Match status ( +2 or more)

Venue (away)

Quality opposition

Venue (away) * Quality opposition

\begin{tabular}{cc} 
& Maintenance \\
\hline$\beta(\mathrm{SE})$ & $95 \% \mathrm{CI}$
\end{tabular}

$\beta(\mathrm{SE})$

$0.056(0.061)$

$-0.009(0.047)$

$-0.060(0.050)$

$0.151(0.064)$

$-0.078(0.033)$

$-0.015(0.003)$

$0.573,0.746$

$0.573,0.746$

$-0.063,0.176$
$-0.101,0.082$

$-0.158,0.038$

$0.025,0.277$

$-0.143,-0.013$

$-0.020,-0.009$

$\begin{array}{cc} & \\ \mathrm{t} & P \\ 14.986 & <0.001 \\ 0.924 & 0.355 \\ -0.202 & 0.840 \\ -1.196 & 0.232 \\ 2.343 & 0.019 \\ -2.350 & 0.019 \\ -5.350 & <0.001 \\ - & -\end{array}$

Estimate SD

0.014

SD

Match

Venue

Quality opposition

0.117

$\begin{array}{cc}- & - \\ 0.022 & 0.147\end{array}$

6.683

0.147
2.585

-

$\mathrm{R}^{2}(\mathrm{~m})$

$\mathrm{R}^{2}(\mathrm{c})$

2.585

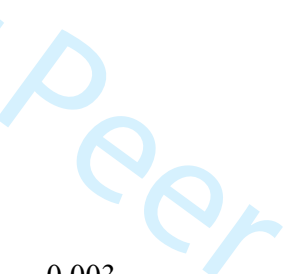

0.003
0.008

$\beta(\mathrm{SE})$

-

$-$

$-$

$0.025(0.005)$

Estimate

0.074

SD

-

0.139

16.272

0.373

4.034
$496(0.090)$
003

Build Up

$95 \% \mathrm{CI}$

$0.335,0.518$

-

$-$

$-0.017,-0.010$

.016

$\beta$, beta coefficient; SE, standard error; CI, confidence interval. Statistical significance set at $P<0.05$.

25 Intercepts represent a draw and playing home. 


\begin{tabular}{|c|c|c|c|c|c|c|c|c|}
\hline \multirow[b]{2}{*}{ Fixed effects } & \multicolumn{4}{|c|}{ Sustained Threat } & \multicolumn{4}{|c|}{ Fast Tempo } \\
\hline & $\beta(\mathrm{SE})$ & $95 \% \mathrm{CI}$ & $\mathrm{t}$ & $P$ & $\beta(\mathrm{SE})$ & $95 \% \mathrm{CI}$ & $\mathrm{t}$ & $P$ \\
\hline Intercept & $2.153(0.100)$ & $0.425,0.630$ & 21.451 & $<0.001$ & $2.872(0.109)$ & $2.659,3.086$ & 26.345 & $<0.001$ \\
\hline Match status ( -2 or more) & - & s & - & - & - & - & - & - \\
\hline Match status (-1) & - & - & - & - & - & - & - & - \\
\hline Match status $(+1)$ & - & - & - & - & - & - & - & - \\
\hline Match status ( +2 or more) & - & - & - & - & - & - & - & - \\
\hline Venue (away) & - & - & - & - & - & - & - & - \\
\hline Quality opposition & $-0.029(0.007)$ & $-0.016,-0.009$ & -4.012 & $<0.001$ & $-0.032(0.013)$ & $-0.057,-0.007$ & -2.549 & 0.012 \\
\hline Venue (away) * Quality opposition & - & - & - & - & - & - & - & - \\
\hline Random effects & Estimate & & & & Estimate & SD & & \\
\hline Match & 0.115 & 0.339 & & & 0.336 & 0.580 & & \\
\hline Venue & - & - & & & - & - & & \\
\hline Quality opposition & - & - & & & 0.006 & 0.081 & & \\
\hline Team & 0.155 & 0.394 & & & 0.073 & 0.269 & & \\
\hline Residuals & 29.240 & 5.407 & & & 31.682 & 5.629 & & \\
\hline $\mathrm{R}^{2}(\mathrm{~m})$ & & 0.002 & & & & 0.00 & & \\
\hline
\end{tabular}

$\beta$, beta coefficient; SE, standard error; CI, confidence interval. Statistical significance set at $P<0.05$. Intercepts represent a draw and playing home. 
Match status (-2 or more)

Match status (-1)

Match status $(+1)$

Match status $(+2$ or more)

Venue (away)

Quality opposition

Venue (away) * Quality opposition

\begin{tabular}{cc} 
& Crossing \\
\hline$\beta(\mathrm{SE})$ & $95 \%$ CI \\
$5.053(0.193)$ & $4.675,5.431$
\end{tabular}

$5.053(0.193)$

$0.130(0.367)$

$4.675,5.431$

$-0.473(0.273)$

$-0.590,0.850$

$-0.026(0.339)$

$-1.008,0.062$

$-0.692,0.639$

$0.589,2.304$

$446(0.437)$

$-0.056(0.015)$

$-0.086,-0.025$

$\begin{array}{ccc} & & \\ \mathrm{t} & P & \beta(\mathrm{SE}) \\ 26.218 & <0.001 & 0.678(0.037) \\ 0.354 & 0.723 & - \\ -1.733 & 0.083 & - \\ -0.077 & 0.938 & - \\ 3.306 & <0.001 & - \\ - & - & -0.119(0.049) \\ -3.600 & <0.001 & -0.023(0.004) \\ - & - & 0.017(0.006)\end{array}$

High Pressure

$95 \%$ CI

0.752

18.09

$\begin{array}{cc}\mathrm{t} & P \\ 18.092 & <0.001 \\ - & - \\ - & - \\ - & - \\ - & - \\ -2.421 & 0.016 \\ -5.150 & <0.001 \\ 2.891 & 0.004\end{array}$

Random effects

Match

Venue

Estimate $\quad \mathrm{SD}$

0.358

SD
0.598

$0.017(0.006)$

-

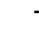

$-0.216,-0.023$

$-0.031,-0.014$

2.891

0.004

$$
\text { Team }
$$$$
\text { - }
$$

0.289

Residuals

0.289
112.747

-
0.538
10.618

$\begin{array}{cc}\text { Estimate } & \mathrm{SD} \\ 0.098 & 0.313 \\ 0.067 & 0.259 \\ <0.001 & 0.015 \\ 0.003 & 0.052 \\ 7.508 & 2.740\end{array}$

$\mathrm{R}^{2}(\mathrm{~m})$

$\mathrm{R}_{(\mathrm{c})}^{2}$

10.618

7.508

$\beta$, beta coefficient; SE, standard error; CI, confidence interval. Statistical significance set at $P<0.05$.

Intercepts represent a draw and playing home. 
The marginal and conditional $\mathrm{R}^{2}$ that measures the effect size of the fixed and random effects respectively, showed very small effect sizes, ranging from 0.002 to 0.035 . Direct Play effectiveness was influenced by match status, venue, and quality of opposition. Direct Play was significantly more effective when losing or winning by 2 or more goals $(\mathrm{P}<0.01$ and $\mathrm{P}<0.05$ respectively), whereas when playing away $(\mathrm{P}<0.01)$ and against stronger opposition $(\mathrm{P}<0.001)$ it was significantly less effective. Specifcally, direct play effectiveness decreased by -0.018 for each position difference in opposition strength based on the teams ranking. For Counterattack, contextual variables match status and quality of opposition influenced effectiveness. Counterattack effectiveness was significantly higher when winning by one goal $(\mathrm{P}<0.01)$ and 2 or more goals $(\mathrm{P}<$ $0.001)$. In contrast, it was less effective $(\mathrm{P}<0.05)$ when losing by one goal and decreased by -0.015 for each position differences in team ranking when facing stronger opposition $(\mathrm{P}<0.05)$. Maintenance effectiveness was significantly influenced by match status, venue, and quality of opposition. Maintenance was more effective $(\mathrm{P}<0.05)$ when winning by 2 or more goals, and less effective $(\mathrm{P}<0.05)$ when playing away. In addition, Maintenance effectiveness decreased $(\mathrm{P}<0.001)$ by -0.015 for each position difference in team ranking when facing stronger opposition.

For Build Up, Sustained Threat and Fast Tempo, only quality of opposition influenced effectiveness. The effectiveness of Build Up, Sustained Threat and Fast Tempo decreased by $-0.025(\mathrm{P}<0.001),-0.029(\mathrm{P}<0.001)$ and $-0.032(\mathrm{P}<0.05)$ respectively for each position difference in team ranking when facing stronger opposition. Crossing was influenced by match status and quality of opposition. Effectiveness for Crossing was significantly higher $(\mathrm{P}<0.001)$ when winning by 2 or more goals. On the other hand, Crossing was less effective $(\mathrm{P}<0.001)$ when facing a stronger opposition, by a value of -0.056 for each position of difference in the ranking. High Pressure was affected by venue and quality of opposition. The effectiveness of High Pressure was significantly lower $(\mathrm{P}<0.05)$ when playing away. Effectiveness was also lower $(\mathrm{P}<0.001)$ when facing a stronger opposition $(-0.023$ for each position of difference in the ranking). Results showed that there was an interaction between venue and quality of opposition for High Pressure. This interaction demonstrates that effectiveness of High Pressure was lower by a value of $-0.004(-0.023+0.017)$ for each position of difference in the ranking when facing a strong opposition and playing away.

\section{Discussion}

The present study examined the effectiveness of styles of play in soccer and the influence of contextual variables (i.e. match status, venue, and quality of opposition). This study showed that the PEI metric, calculated from Expected Goals (xG) and Ball Movement Points (BMP), could be used to measure the effectiveness of styles of play in soccer, and how this changes under different contextual variables. Similar to previous research, ${ }^{21,22}$ the results of this study highlight the importance of employing new metrics to evaluate the effectiveness of tactical behaviour in soccer, while controlling for variables that could affect performance. Influence of contextual variables on soccer performance has been 
analysed before ${ }^{2}$, and previous studies determined that playing home is advantageous for teams, ${ }^{35,36}$ and that playing against strong opposition influence negatively the team performance. ${ }^{36,37}$ This study found similar results considering also the styles of play. To our knowledge, no previous study has evaluated the effectiveness of styles of play in soccer and the influence of contextual variables.

Direct play showed a mean effectiveness of 0.648 per possession when drawing and playing home. The effectiveness of direct play significantly increased in both extreme match status situations of losing by two goals or more and winning by two goals or more. A possible explanation could be that when teams score, losing teams often see increased possesion ${ }^{38,39}$ in an attempt to score as soon as possible and reduce their deficit. Therefore, increased posession in attacking zones leaves space behnind adavancing defenders for the opposition to exploit. In contrast, teams losing by two goals or more, with the aim of scoring quickly, would accumulate more players in the attacking third and use direct play to their benefit. Previous studies investigated the effectiveness of direct and possession play but did not assess how contextual variables influenced each of these styles. Most reported that possession play was more effective in comparison with direct play. ${ }^{6,40,41}$ However, others showed contradictory results indicating that direct play was more effective. ${ }^{42,43}$ These contradictory results may be due to the different ways of evaluating effectiveness, or the different leagues used in the sample for the analysis. Sarmento et al. ${ }^{44}$ found that the chance of an offensive sequence ending effectively were higher in the Spanish, Italian and English leagues in comparison with the Champions League. More competitive leagues, such as Champions League could affect the effectiveness measures.

Counterattack seemed to be more effective when teams were winning and like direct play, winning teams take advantage of space behind the opponent when they are in advanced positions on the pitch. In contrast, the effectiveness of counterattack decreased when teams were losing by one goal. Teams with a minimum score advantage retreat their position closer to their own goal and consequently, the defence was better prepared and more balanced ${ }^{24}$ when facing opposition counterattacks. These results contrast with previous research that investigated effectiveness in counterattacks and did not find significant effects among contextual variables. ${ }^{45}$ Maybe this could be due to the small sample size employed in the study (30 matches) and the possible differences between the USA MLS league and EPL.

Maintenance and crossing styles of play were more effective when teams were winning by two or more goals. Teams could be using maintenance to keep possession of the ball closer to their own goal, allowing the opponent to press high so that it leaves space behind them. In addition, the high press by the losing opponent would leave fewer players for defending crosses, therefore increasing the effectiveness of this style of play. Liu et al. ${ }^{12}$ reported a negative relationship between crosses and the probability of winning, however when match status alters it can become an effective tactic. Surprisingly, there was no significant effect on the effectiveness of build up, sustained threat, fast tempo, and high pressure styles of play when match status altered. Previous research reported that teams increased the use of possession styles when losing and decreased the use of possession and high pressure styles when winning ${ }^{7}$. However, our 
results showed no difference in the effectiveness of these styles of play under different match status circumstances. Apparently, the effectiveness of these possession-based styles of play and high pressure was not influenced by winning or losing states of teams during match-play.

The effectiveness of direct play, maintenance, and high pressure decreased when teams played away from home. The home advantage phenomenon could explain this effect and a positive association with match outcome and playing at home has been reported previously in soccer. ${ }^{46-48}$ Our findings partially agree with previous research and showed that venue influenced the effectiveness of only three styles of play analysed. It is possible that for certain styles of play, venue has less influence on effectiveness, whereas other contextual variables such as match status or quality of opposition have a greater influence. Therefore, more research should be carried out into the influence of venue on the effectiveness of styles of play.

Quality of opposition is the only contextual factor the influences all the styles of play. They all showed a decrease in effectiveness when facing a stronger opposition and an increase against weaker teams. The results showed an effect that ranged from -0.015 to -0.056 per position in the final ranking when facing a stronger opposition. Therefore, the effect increased when the difference in ranking between two teams was greater. As we might expect, better teams with better players have better effectiveness values for all styles irrelevant toof their preferred style of play. Our findings are in line with the quality of opposition effect on match outcome in UEFA Champions League matches (GarciaRubio et al. ${ }^{35}$. In addition, we showed an interaction between venue and quality of opposition for high pressure. Unexpectedly, the interaction diminished the decrease in effectiveness for high pressure due to the quality of opposition. In other words, for teams playing away, the decrease of effectiveness when using high pressure style of play was lower in comparison when playing at home. It seemed that venue was a more important factor in combination with quality of opposition when teams played away. This is supported by research highlighting the impact of the home advantage phenomenon in soccer. ${ }^{49}$

This study presents a novel approach for measuring the effectiveness of styles of play, however some caution must be observed. The effect sizes for the mixed models were small for all the styles of play, showing that there was large variation unexplained by the model. The nature of soccer and its complex and chaotic organisations ${ }^{50}$ could be a reason for this unexplained variation and highlights the complex nature of fully evaluating performance in soccer. Previous research showed multiple methods for analysing multiple aspects involved in soccer performance such as formations ${ }^{51}$ styles of play, ${ }^{3}$ or team coordination. ${ }^{52}$ The use of these different approaches to evaluating several aspects, proves the difficulty of analysing team performance in this sport. Future research should consider that analysing soccer performance is a complex problem due to all the aspects involved and therefore, employ appropriate approaches to deal with this. Moreover, the $\mathrm{xG}$ and BMP metrics are based on shooting data and it is possible that good opportunities not ending in a shot should be considered when modelling effectiveness measures. The PEI, as a combination of BMP and $\mathrm{xG}$, is a proposal for measuring the effectiveness of styles of play based on team possessions. Other 
approaches using different modelling and considering more variables and playing situations such as ball control, pressure, or players density, apart from shooting events, could provide better quantification of performance in soccer. ${ }^{53}$ The approach employed in this study used event data and this present some advantages in comparison with the use of player tracking data. Although player tracking data provides more accurate information, the use of event data is more extended among the coaches and performance analysts, and therefore, it would entail a simpler and cheaper solution to practitioners to analyse the effectiveness of attacking actions. In addition, the data collected for the analysis is only one full season from the 2015-2016 EPL. Therefore, the generalisation of results to other leagues and seasons is limited, ${ }^{54}$ however, this approach can be used to model data from other leagues and seasons for comparison purposes. Another limitation of the approach employed in this work is the limited reproducibility of future research as a result of the difficulty to access the data used in this study. Moreover, due to the proprietary metrics and data used, and their limited availability; it is difficult to check for reliability, validity and objectivity of data.

More importantly, the models developed in this study have some practical implications. For example, coefficients for individual teams can be extracted to identify the effectiveness of styles of play across different contextual situations. Teams can also be compared to evaluate how effectively they employ their styles of play under specific contextual situations. For example, team A was the most effective when using Direct Play and showed an increased effectiveness 0.15 above the average, when compared to other teams. In addition, performance analysts, coaches and other soccer practitioners could employ similar approaches, using effectiveness metrics alongside styles of play measures, to evaluate their team and the opposition's tactical behaviour. This useful information could be used to assess how effective teams are when applying styles of play during match play, and which strategies are better under specific circumstances. Information from these analytical models should be considered cautiously and should serve as support for making tactical decisions. A team may feel comfortable using a specific style of play in a certain moment of play and could employ it even though data might suggest otherwise. Finally, this analysis of performance could aid the tactical preparation for upcoming matches and the development of training drills to enhance the tactical play of soccer teams.

\section{Conclusions}

This study used a novel approach to measure styles of play effectiveness and the influence of contextual variables. Moreover, PEI (based on xG and BMP metrics) could be useful for measuring the effectiveness of team possessions and in combination with styles of play scores, an effectiveness measure can be created for team possessions. Styles of play analysed in this study (i.e. Direct Play, Counterattack, Maintenance, Build Up, Sustained Threat, Fast Tempo, Crossing, and High Pressure) showed different effectiveness depending on match status, venue and quality of opposition.

\section{Acknowledgements}


The authors would like to thank STATS LLC for providing access to the data used in this research. This study is part of the PhD thesis of Javier Fernandez-Navarro of the Biomedicine programme of the University of Granada, Spain.

\section{Funding}

This study was supported by the Spanish Ministry of Education (FPU13/05369).

\section{Disclosure of interest}

The authors report no conflict of interest.

\section{References}

1. Rein R and Memmert D. Big data and tactical analysis in elite soccer: future challenges and opportunities for sports science. SpringerPlus 2016; 5: 13.

2. Sarmento H, Marcelino R, Anguera MT, et al. Match analysis in football: a systematic review. J Sport Sci 2014; 32: 1831-1843.

3. Fernandez-Navarro J, Fradua L, Zubillaga A, et al. Attacking and defensive styles of play in soccer: analysis of Spanish and English elite teams. J Sport Sci 2016; 34: 21952204.

4. Hewitt A, Greenham G and Norton K. Game style in soccer: what is it and can we quantify it? Int J Perf Anal Spor 2016; 16: 355-372.

5. Gollan S, Ferrar K and Norton K. Characterising game styles in the English Premier League using the "moments of play" framework. Int J Perf Anal Spor 2018; 18 : 998-1009.

6. Kempe M, Vogelbein M, Memmert D, et al. Possession vs. Direct Play: Evaluating Tactical Behavior in Elite Soccer. International Journal of Sports Science 2014; 4: 35-41.

7. Fernandez-Navarro J, Fradua L, Zubillaga A, et al. Influence of contextual variables on styles of play in soccer. Int J Perf Anal Spor 2018; 18: 423-436.

8. Gomez MA, Mitrotasios M, Armatas V, et al. Analysis of playing styles according to team quality and match location in Greek professional soccer. Int J Perf Anal Spor 2018; 18: 986-997.

9. Castellano J, Casamichana D and Lago C. The Use of Match Statistics that Discriminate Between Successful and Unsuccessful Soccer Teams. J Hum Kinet 2012; 31: 139-147.

10. Harrop K and Nevill A. Performance indicators that predict success in an English professional League One soccer team. Int J Perf Anal Spor 2014; 14: 907-920.

11. Lago-Ballesteros J and Lago-Peñas C. Performance in Team Sports: Identifying the Keys to Success in Soccer. J Hum Kinet 2010; 25: 85-91.

12. Liu H, Hopkins WG and Gomez MA. Modelling relationships between match events and match outcome in elite football. Eur J Sport Sci 2016; 16: 516-525.

13. Collet $\mathrm{C}$. The possession game? A comparative analysis of ball retention and team success in European and international football, 2007-2010. J Sport Sci 2013; 31: 123136. 
14. Vogelbein M, Nopp S and Hokelmann A. Defensive transition in soccer - are prompt possession regains a measure of success? A quantitative analysis of German Fussball-Bundesliga 2010/2011. J Sport Sci 2014; 32: 1076-1083.

15. Casal CA, Maneiro R, Arda T, et al. Analysis of Corner Kick Success in Elite Football. Int J Perf Anal Spor 2015; 15: 430-451.

16. Casal CA, Maneiro R, Arda T, et al. Effectiveness of Indirect Free Kicks in Elite Soccer. Int J Perf Anal Spor 2014; 14: 744-760.

17. White $\mathrm{S}$ and $\mathrm{O}^{\prime}$ Donoghue $\mathrm{P}$. Factors influencing penalty kick success in elite soccer. In: Nunome H, Drust B and Dawson B (eds) Science and Football VII. London: Routledge, 2013, pp.237-242.

18. Clemente FM, Couceiro MS, Martins FML, et al. Measuring Tactical Behaviour Using Technological Metrics: Case Study of a Football Game. Int J Sports Sci Sci Coach 2013; 8: 723-739.

19. Clemente FM, Couceiro MS, Martins FML, et al. Measuring Collective Behaviour in Football Teams: Inspecting the impact of each half of the match on ball possession. Int J Perf Anal Spor 2013; 13: 678-689.

20. Rein R, Raabe D and Memmert D. "Which pass is better?" Novel approaches to assess passing effectiveness in elite soccer. Hum Mov Sci 2017; 55: 172-181.

21. Pollard R and Reep C. Measuring the Effectiveness of Playing Strategies at Soccer. J R Stat Soc Ser D-Stat 1997; 46: 541-550.

22. Szczepanski L. Measuring the effectiveness of strategies and quantifying players' performance in football. Int J Perf Anal Spor 2008; 8: 55-66.

23. Rathke A. An examination of expected goals and shot efficiency in soccer.

Journal of Human Sport and Exercise 2017; 12: S514-S529.

24. Tenga A, Holme I, Ronglan LT, et al. Effect of playing tactics on goal scoring in Norwegian professional soccer. J Sport Sci 2010; 28: 237-244.

25. Tenga A, Holme I, Ronglan LT, et al. Effect of playing tactics on achieving scorebox possessions in a random series of team possessions from Norwegian professional soccer matches. J Sport Sci 2010; 28: 245-255.

26. Bradley P, O'Donoghue $\mathrm{P}$, Wooster B, et al. The reliability of ProZone

MatchViewer: a video-based technical performance analysis system. Int J Perf Anal Spor 2007; 7: 117-129.

27. Di Salvo V, Collins A, McNeill B, et al. Validation of Prozone : A new videobased performance analysis system. Int J Perf Anal Spor 2006; 6: 108-119.

28. R Core Team. R: A Language and Environment for Statistical Computing. Vienna, Austria: R Foundation for Statistical Computing, 2017.

29. Bates D, Machler M, Bolker BM, et al. Fitting Linear Mixed-Effects Models Using lme4. J Stat Softw 2015; 67: 1-48.

30. Heck RH, Thomas SL and Tabata LN. Multilevel and Longitudinal Modeling with IBM SPSS. 2nd ed. New York, NY: Routledge (Taylor \& Francis Group), 2014.

31. Akaike H. Information Theory and an Extension of the Maximum Likelihood Principle. In: Second International Symposium on Information Theory (eds Petrov BN and Csaki F), Budapest, 1973, pp.267-281. Akademiai Kiado.

32. Field A. Discovering Statistics Using IBM SPSS Statistics. 4th ed. London: SAGE Publications, 2013, p.952. 
33. Nakagawa S and Schielzeth H. A general and simple method for obtaining R2 from generalized linear mixed-effects models. Methods Ecol Evol 2013; 4: 133-142.

34. Johnson PCD. Extension of Nakagawa \& Schielzeth's R-GLMM(2) to random slopes models. Methods Ecol Evol 2014; 5: 944-946.

35. Garcia-Rubio J, Gomez MA, Lago-Peñas C, et al. Effect of match venue, scoring first and quality of opposition on match outcome in the UEFA Champions League. Int $J$ Perf Anal Spor 2015; 15: 527-539.

36. Lago-Peñas C, Lago-Ballesteros J and Rey E. Differences in Performance Indicators between Winning and Losing Teams in the UEFA Champions League. J Hum Kinet 2011; 27: 137-148.

37. Zhou CJ, Zhang SL, Lorenzo Calvo A, et al. Chinese soccer association super league, 2012-2017: key performance indicators in balance games. Int J Perf Anal Spor 2018; 18: 645-656.

38. Lago C. The influence of match location, quality of opposition, and match status on possession strategies in professional association football. J Sport Sci 2009; 27: 14631469.

39. Lago C and Martin R. Determinants of possession of the ball in soccer. $J$ Sport Sci 2007; 25: 969-974.

40. Sgro F, Aiello F, Casella A, et al. Offensive strategies in the European Football Championship 2012. Percept Mot Skills 2016; 123: 792-809.

41. Hughes M and Franks I. Analysis of passing sequences, shots and goals in soccer. J Sport Sci 2005; 23: 509-514.

42. Yue ZY, Broich H and Mester J. Statistical Analysis for the Soccer Matches of the First Bundesliga. Int J Sports Sci Sci Coach 2014; 9: 553-560.

43. Lago-Ballesteros J, Lago-Peñas $\mathrm{C}$ and Rey E. The effect of playing tactics and situational variables on achieving score-box possessions in a professional soccer team. $J$ Sport Sci 2012; 30: 1455-1461.

44. Sarmento H, Figueiredo A, Lago-Penas C, et al. Influence of Tactical and Situational Variables on Offensive Sequences During Elite Football Matches. J Strength Cond Res 2018; 32: 2331-2339.

45. Gonzalez-Rodenas J, Lopez-Bondia I, Calabuig F, et al. Association between playing tactics and creating scoring opportunities in counterattacks from United States Major League Soccer games. Int J Perf Anal Spor 2016; 16: 737-752.

46. Lago-Peñas C, Gomez MA and Pollard R. Home advantage in elite soccer matches. A transient effect? Int J Perf Anal Spor 2017; 17: 86-95.

47. Pollard R. Worldwide regional variations in home advantage in association football. J Sport Sci 2006; 24: 231-240.

48. Pollard R and Gomez MA. Home advantage in football in South-West Europe: Long-term trends, regional variation, and team differences. Eur J Sport Sci 2009; 9: 341352.

49. Jamieson JP. The Home Field Advantage in Athletics: A Meta-Analysis. J Appl Soc Psychol 2010; 40: 1819-1848.

50. Memmert D, Lemmink KAPM and Sampaio J. Current Approaches to Tactical Performance Analyses in Soccer Using Position Data. Sports Med 2017; 47: 1-10. 
51. Bialkowski A, Lucey P, Carr P, et al. Identifying Team Style in Soccer Using Formations Learned from Spatiotemporal Tracking Data. 2014 IEEE International Conference on Data Mining Workshop. Shenzhen, China2014, p. 9-14.

52. Sampaio J and Macas V. Measuring Tactical Behaviour in Football. International Journal of Sports Medicine 2012; 33: 395-401.

53. Link D, Lang S and Seidenschwarz P. Real Time Quantification of Dangerousity in Football Using Spatiotemporal Tracking Data. PLoS One 2016; 11: 16.

54. Mackenzie R and Cushion C. Performance analysis in football: A critical review and implications for future research. J Sport Sci 2013; 31: 639-676. 


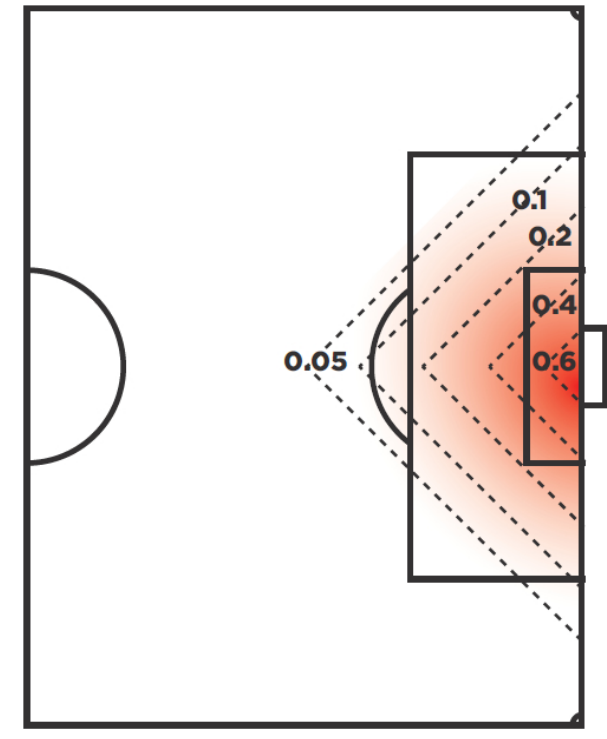

\section{SHOTS}

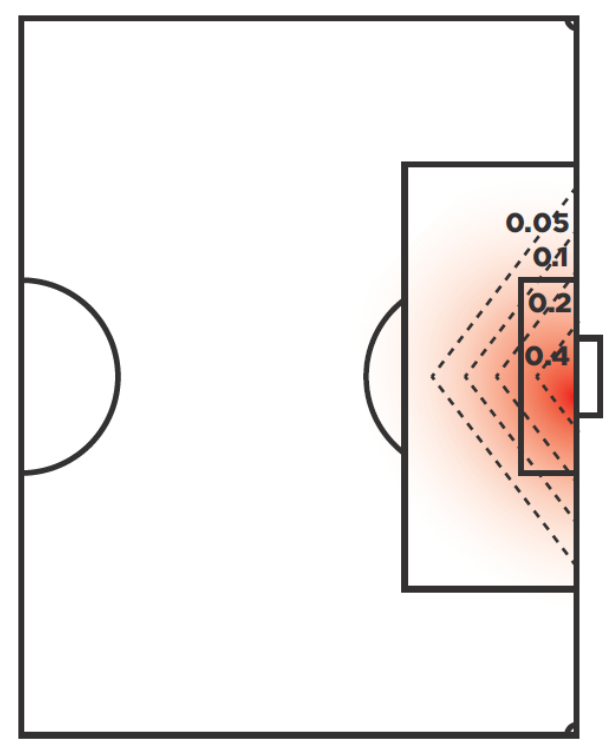

\section{HEADERS}

Figure 1. Expected conversion probabilities with the foot (left image) and headers (right image) depending on the location on the pitch.

$233 \times 146 \mathrm{~mm}(120 \times 120 \mathrm{DPI})$ 


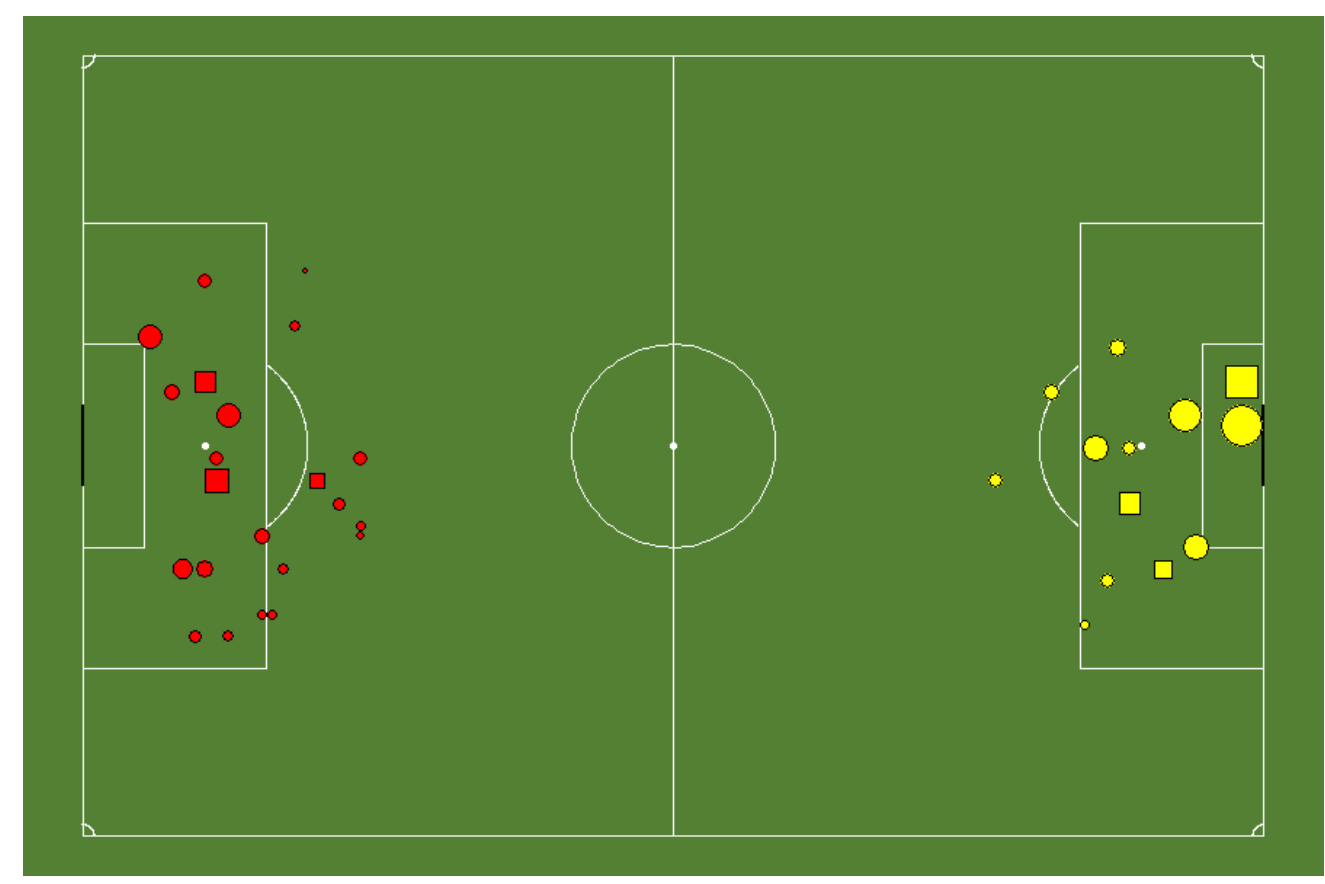

Figure 2. xG values of shots and headers in a match. Team A in red and Team B in yellow. A larger size of the symbol represents a higher probability to score a goal. Squares represent goals.

$236 \times 156 \mathrm{~mm}(96 \times 96 \mathrm{DPI})$ 


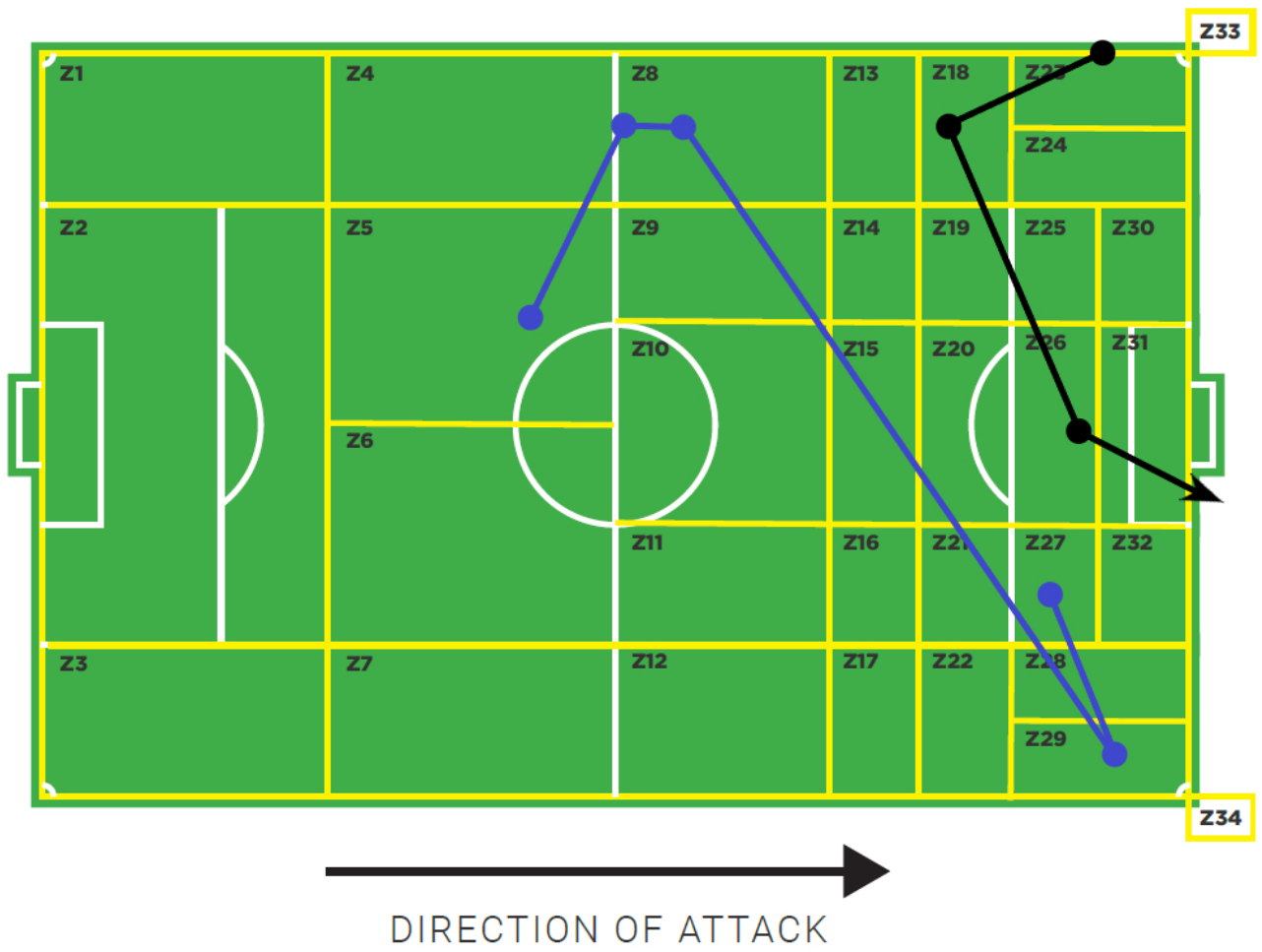

Figure 3. Pitch division to calculate Ball Movement Points (BMP). Black chain of ball moves ending in a header shows a total of 0.15 PEI, $(0.004+0.032)$ BMP $+0.114 \times$. Blue chain of ball moves ending in a possession lost shows a total of -0.009 PEI, $(0.001+0.01+0.011-0.031) B M P$.

\section{$266 \times 196 \mathrm{~mm}(96 \times 96 \mathrm{DPI})$}

